\title{
MAGNETIC BALANCE FOR CURIE TEMPERATURE IN AMORPHOUS MATERIAL RESEARCH
}

\author{
Bartosz PŁOSZAJ ${ }^{1, *}$ \\ ${ }^{1}$ Chair of Physics, Faculty of Production Engineering and Materials Technology, Czestochowa University of \\ Technology, 19 Armii Krajowej Str., 42-200 Częstochowa, Poland, bartosz.ploszaj@pcz.pl
}

\begin{abstract}
Farraday's magnetic balance is the well-known device which allow to obtain Curie temperature. This temperature is crucial parameter for describing properties of soft magnetic alloys and allow to show their potential field of application. In this research main scope is on $\mathrm{Fe}$-based amorphous material. In this group is still potential in improvement of their properties, e.g. manufacturability, lowering coercivity, decreasing cost of production in context of application in power generation and conversion as well as electronic. This work includes not only research done on magnetic balance, but also ones conducted on x-ray diffractometry. Alloy was produced by arc melting and injection under protective atmosphere of argon. Results are promising and are presented and discussed in this paper.
\end{abstract}

Keywords: Farraday's magnetic balance, Curie temperature, soft magnetic alloys, amorphous materials

\section{Introduction}

A Faraday magnetic balance is a device dedicated for measuring magnetic susceptibility which is related to the force experienced by a substance within magnetic field [1]. In such balance the field is homogeneous. The sample is placed in region which the product of the field strength and field gradient in the $z$ direction is constant, which follows from shape of the pole pieces of the magnet. In case of this device force depends only on the total mass of the analysed material. This mtehod has following advantages: sensitivity, high reproducibility [2]. By using this device it is possible to do research in which Curie temperature can be obtained. The one is crucial parameter describing ferromagnetic materials. By knowing this temperature it is possible to determine stability of ferromagnetic state and also stability of the existence of magnetic domains. At certain, high enough, temperature domains of the ferromagnetic material will dissapear and material will become to be paramagnetic as the second form of phase transition will occur in that case [3-5]. In this work Fe-based amorphous alloy is considered. Such based group of alloys have wide application potential. Good mechanical properties [6-8] or high corrosion resistance [8-9] are possible to obtain and depends on content of $\mathrm{Fe}$, transition metals as well as non-metals. This group have potential in properties improvement such as manufacturability, lowering coercivity, decreasing cost of production in context of application in power generation and conversion as well as electronic. Amorphous materials made in form of strips or tapes can be used to build lowloss transformers cores, although due to their limited size have to be packed into groups to get around their size limitations. Creating such packets of amorphous material resulting in the 
entrapment of air between package layers, hence resulting in unnecessary heating of the core while operation at higher frequencies. To overcome problem of excess heating bulk materials can be produced and used [9-10]. Producing of amorphous materials as well as bulk amorphous materials has long history and seems to be interesting. Rapidly-cooling methods for liquid alloys made possible to produce samples or final products with different shapes and dimensions. The easiest one to produce are amorphous alloys of small cross-sectional thickness. Thin layers and thin tapes form ferromagnetic amorphous materials were produce first [11]. Obtaining thin layer materials was not only time-consuming and laborious but also required expensive equipment. From this point of view, producing tapes by using e.g. melt-spinning method (where unidirectional cooling of liquid alloy on the surface of rotating cylinder occurs) is less timeconsuming and simpler but also more cost-effective [12]. Melt-spinning method has cooling rates in range between $10^{4}$ to $10^{6} \mathrm{~K} / \mathrm{s}$ and obtained tapes may have thickness in the range between 12 to $100 \mu \mathrm{m}$. In this thickness range tapes can still maintaining their integrity [13]. 1989 was the year when A. Inoue of the University of Tohoku, and his colleagues presented principles which enable to produce materials exceeding limited, till then, thickness of $100 \mu \mathrm{m}$. There are three principles including introducing more than three components to the composition of the alloy, selection of appropriate differences between atomic radii and negative mixing heat of alloying elements. Reduction of migration of atoms within the alloy as well as formation of energetically favoured systems with long-range interactions between atoms, increasing in viscosity during solidification of the alloy, blockage of the atoms movement are the result of mentioned principles, respectively [14-15]. It can be state that from 1989 an era of bulk amorphous materials occurred.

This paper presents the results of research on the saturation magnetic polarisation, as a function of temperature as well as x-ray diffractometer analysis for bulk amorphous $\mathrm{Fe}_{60} \mathrm{Co}_{10} \mathrm{Y}_{8} \mathrm{Ni}_{2} \mathrm{~B}_{20}$ alloy.

\section{Materials and Methods}

Alloy was produced in multistage process. The first one is focused on ingot production, second one is concentrated on production of rapidly-cooled alloy and the last one is directly dedicated for sample preparation.

In the first stage alloying components are weighted with the accuracy to 0.0001 grams. All elements have purity not lower than 99,9\%. Future alloy elements are placed on water-cooled copper plate inside dedicated pocket which is mounted inside working chamber. When components are carefully placed chamber is closed and pumped to obtain high vacuum inside. Chamber is rinsed at least three times with argon and after each rinsing is pumped again. High vacuum and rinsing of chamber allow to obtain high quality ingots together with pre-melting of pure titanium inside chamber bestead at the same time when alloying components where. The role of titanium is to absorb remaining impurities located within the volume of chamber. Elements are melted initially to obtain ingot form. However, to obtain high quality one is necessary to remelt it at least four times (two times per side) and with melting of titanium between each reverse. Re-melting procedure allow to obtain well-mixed ingot. The homogeneity of ingot has great impact on the reproducibility while considering production of rapidly-cooled materials.

In the second stage ingots are cleaned mechanically and via ultrasonic cleaner. Then are divided into smaller parts to produce rods by the use of injection method. In injection method rapidly-cooled alloy is produced within the cooling rate of $10^{-1}$ to $10^{3} \mathrm{~K} / \mathrm{s}$. It this method inside 
quartz crucible ended with hole about $1 \mathrm{~mm}$ diameter batch is placed. Such crucible is located inside working chamber and the batch is at the level where copper coil is installed. By the use of eddy current batch is melted. To inject batch to water-cooled copper mold suitably selected argon pressure is used. To keep alloy high purity whole process is done under protective atmosphere of argon. Such atmosphere is produced by pumping chamber by the use of valves and pump system. At least one rinsing is done to be sure that the chamber is clear enough for the process.

In the third step obtained in injection method rods are carefully selected, mechanically cleaned as well as in ultrasonic cleaner, then inside mortar crucible subjected to low energy milling. Powdered samples are analysed in x-ray device as which in this case should be highlighted in magnetic balance presented on Fig. 1 and Fig. 2.

Fig. 2 contains schematic representation of Sucksmith's type magnetic balance. In such one, restoring force is given by the elasticity of a ring denoted by "r", carrying the sample denoted by "s". Deviation of light beam is given by the reflections from mirrors placed on the ring where strongest deformation occurs. There is no compensation of the force and measurement is done by the reading of index displacement on the scale. Such balance has not quite accuracy according to other types of available scales. [17].

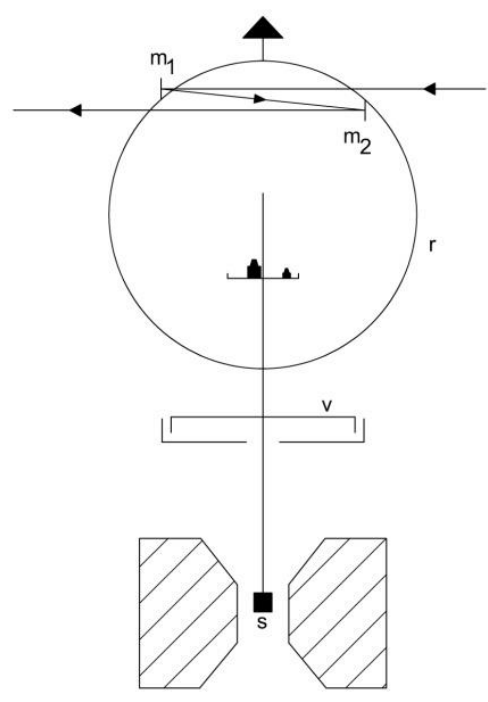

Fig. 1. Schematic representation of Suckmith's type magnetic balance [17]

Sucksmith's type balance initially had some disadvantages such as difficulties in setting of zero point, not great secure of basket with sample mounted on rod while subjected to magnetic field as well as lack of sensitivity setting other than change of the springy ring [18]. Although existence of such drawback results obtained in the device have enough accuracy. Device used in this case (schematic representation of Fig. 2) have some improvements. Heating temperature is controlled by proportional-integral-derivative controller THERMOS. Sample placed in platinum bucket is heated inside heater on quartz core with external stainless steel cover with dedicated insulation layer inside. Such improvement resulting in stable increment of temperature in function of time. Also vacuum system is improved. Instead of rubber hoses dedicated elastic stainless steel cord are in use. Such improvement resulting in more stable deviation readings. There are also more minor improvements that reducing mentioned above drawbacks. 


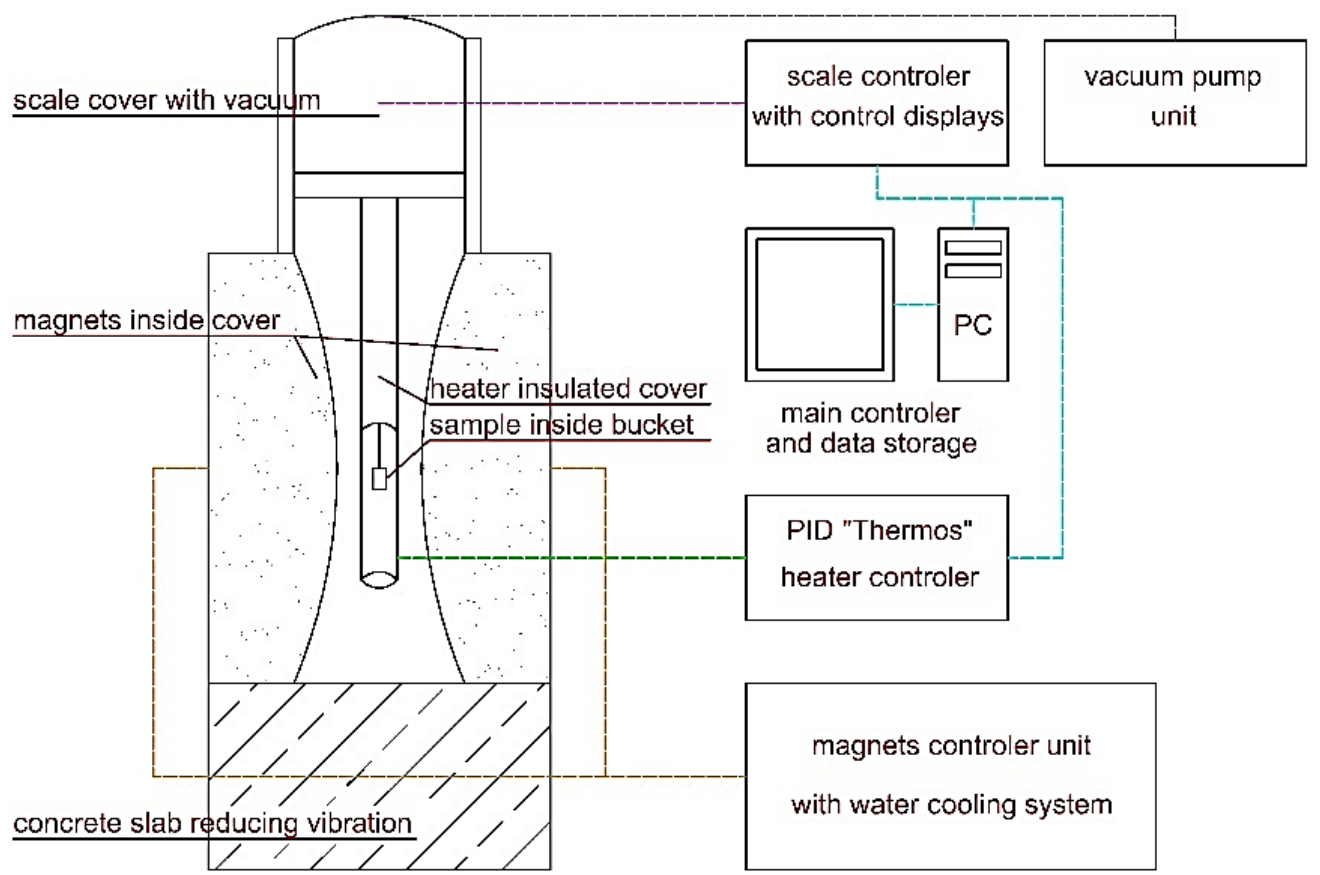

Fig. 2. Schematic representation of Farraday's magnetic balance setup

\section{Results and Discussions}

Alloy with the formula $\mathrm{Fe}_{60} \mathrm{Co}_{10} \mathrm{Y}_{8} \mathrm{Ni}_{2} \mathrm{~B}_{20}$ was selected for purpose of this research. By the use of an arc furnace 10 gram homogenous ingot was produced (Fig. 3.a). Components used to produce this alloy were with $99,99 \%$ purity. Water-cooled copper mold was used for producing rapidly-cooled alloy in the injection method. Sample material was cast in the shape of rod with the diameter in cross-section about $1 \mathrm{~mm}$ (Fig 3.b). Obtained rods were cleaned mechanically and via ultrasonic cleaner.

a)

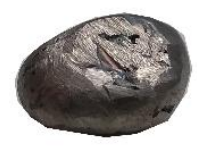

b)

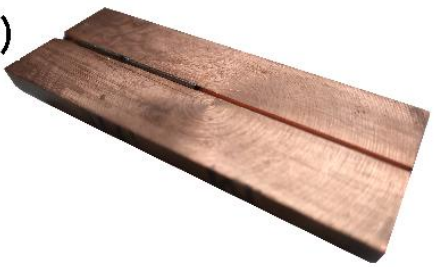

c)

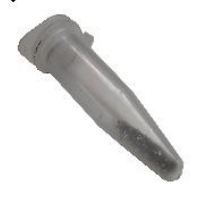

Fig. 3. $\mathrm{Fe}_{60} \mathrm{Co}_{10} \mathrm{Y}_{8} \mathrm{Ni}_{2} \mathrm{~B}_{20}$ alloy produced: a) mechanically cleaned ingot, b) rod form amorphous alloy on the half of copper mold

c) ready to measure alloy's powder

To obtain x-ray diffractometer and thermomagnetic curves alloy in rod form was subjected to low energy milling in agate mortar. Obtained powder (Fig 3.c) as soon as produced was analysed with the use of BRUKER D8 ADVANCE apparatus operating in the Bragg- 
Brentano $(\mathrm{CuK} \alpha)$ geometry for the x-ray examinations and Sucksmith's type magnetic scale equipped with proportional-integral-derivative controller THERMOS.

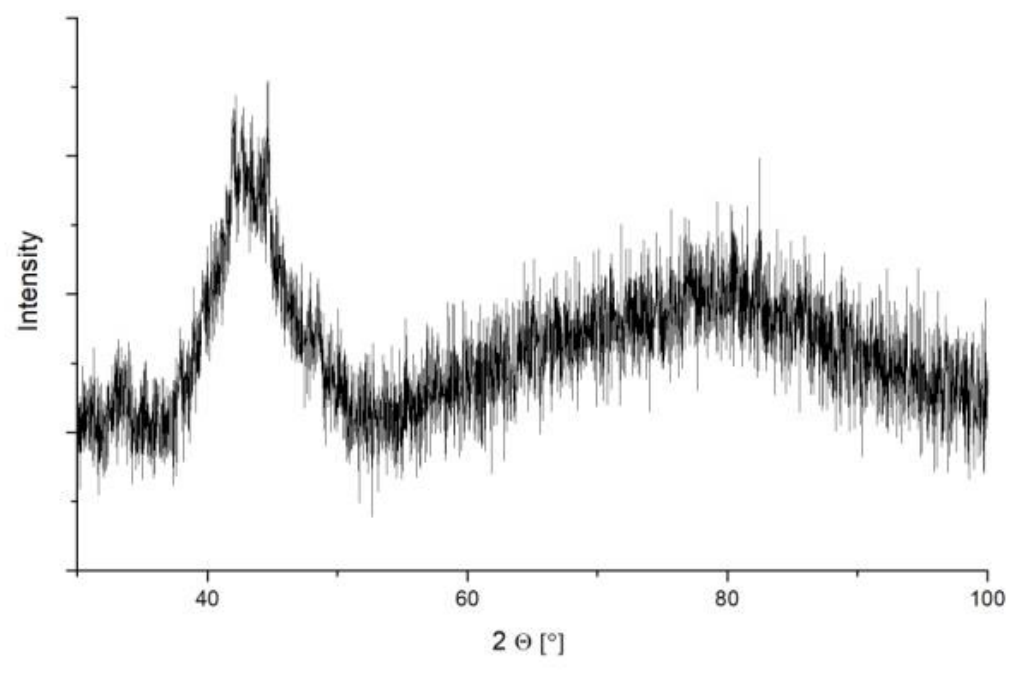

Fig. 4. Diffractometer of $\mathrm{Fe}_{60} \mathrm{Co}_{10} \mathrm{Y}_{8} \mathrm{Ni}_{2} \mathrm{~B}_{20}$

Presented in Fig. 4 diffraction pattern for $\mathrm{Fe}_{60} \mathrm{Co}_{10} \mathrm{Y}_{8} \mathrm{Ni}_{2} \mathrm{~B}_{20}$ alloy is valid for amorphous type. From this pattern it can be state that there is lack of long-range atom order as well as crystalline phases. There is visible only one maxima near angle $2 \Theta 45^{\circ}$.

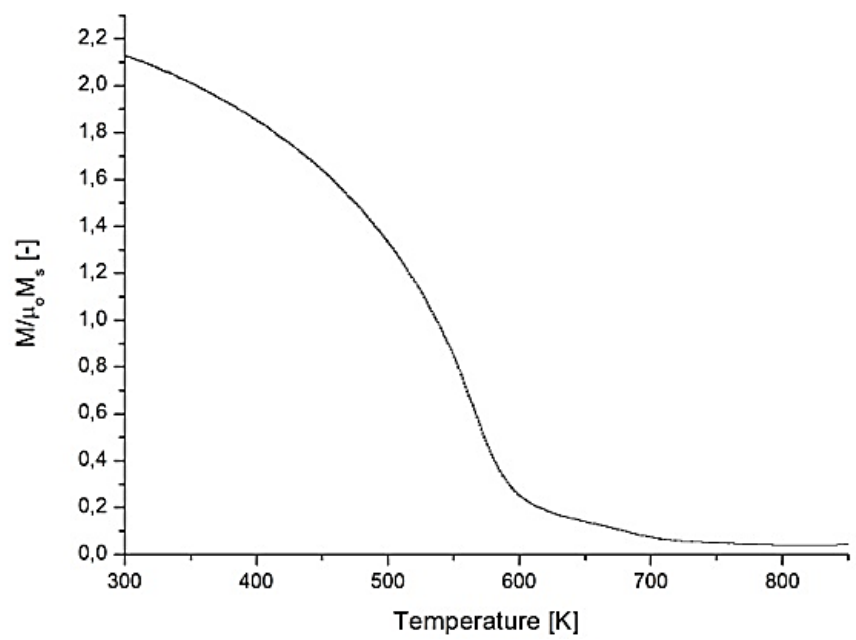

Fig. 5. Thermomagnetic curve obtained for $\mathrm{Fe}_{60} \mathrm{Co}_{10} \mathrm{Y}_{8} \mathrm{Ni}_{2} \mathrm{~B}_{20}$

Thermomagnetic properties of $\mathrm{Fe}_{60} \mathrm{Co}_{10} \mathrm{Y}_{8} \mathrm{Ni}_{2} \mathrm{~B}_{20}$ alloy were analysed on Fig. 5 basis where saturation magnetic polarisation, as a function of temperature is visible. Thermomagnetic curve have typical shape for amorphous material and only single Curie temperature region occurs in range between $600-650 \mathrm{~K}$. Analysis of this curve determine that alloy do not crystallise within set temperature range. Similarly to statement for Fig. 4 there was not any area characterised by 
long-range order, which comes from the fact that in region of the transition from ferromagnetic to the paramagnetic state, magnetisation was reduced almost to zero.

\section{Conclusions}

Use of Farraday's magnetic balance allows to obtain Curie temperature from plotted thermomagnetic curve for selected $\mathrm{Fe}_{60} \mathrm{Co}_{10} \mathrm{Y}_{8} \mathrm{Ni}_{2} \mathrm{~B}_{20}$ alloy. This temperature is in range between $600-650 \mathrm{~K}$. Range of temperature rather than discrete value in case of amorphous material should be in use. X-ray diffraction pattern is typical for amorphous material, which met the approach of the research that the main scope is on Fe-based amorphous material. Further research focused more on manufacturability, decreasing cost of production can result in commercial application of such alloy. There is also potential to conduct another research on such alloy by the check of it properties after heat treatment with different parameters.

\section{References:}

[1] C.J. O'Connor, S.J. Lippard, Magnetic susceptibility measurements. Progress in Inorganic Chemistry. 29, Wiley, 1982, p. 203.

[2] R.L Carlin, Magnetochemistry, Springer, 1986, p. 3

[3] F. Wang, A. Inoue, Y. Han, F. Kong, S. Zhu, E. Shalaan, F. Al-Marzouki, A. Obaid, Excellent soft magnetic Fe-Co-B-based amorphous alloys with extremely high saturation magnetization above $1.85 \mathrm{~T}$ and low coercivity below $3 \mathrm{~A} / \mathrm{m}$, Journal of Alloys and Compounds vol. 711, 2017, pp. 132-142.

[4] M. E. McHenry, M. A. Willard, D. E. Laughlin, Progress in Materials Science 44, 1999, pp. 291-433.

[5] M. Nabialek, K. Jeż, B. Jeż, The Influence of Structure Defects on Magnetization Process of Bulk Amorphous $\mathrm{Fe}_{63} \mathrm{Co}_{8} \mathrm{Y}_{8} \mathrm{~W}_{1} \mathrm{~B}_{20}$ Alloy, ACTA PHYSICA POLONICA A 135(2), 2019, pp. 136-138.

[6] S. Hasani, P. Rezaei-Shahreza, A. Seifoddini, M. Hakimi, Enhanced glass forming ability, mechanical, and magnetic properties of $\mathrm{Fe}_{41} \mathrm{Co}_{7} \mathrm{Cr}_{15} \mathrm{Mo}_{14} \mathrm{Y}_{2} \mathrm{C}_{15} \mathrm{~B}_{6}$ bulk metallic glass with minor addition of $\mathrm{Cu}$, Journal of Non-Crystalline Solids 497, 2018, pp. 40-47.

[7] S. Hasani, P. Rezaei-Shahreza, A. Seifoddini, Effect of $\mathrm{Cu}$ Presence on Evolution of Mechanical and Magnetic Properies in a Novel Fe-Based Bulk Metallic Glass During Partial Annealing Process, Metallurgical and Materials Transactions A 50, 2019, pp. 63 -71 .

[8] Z. Jaafari, A. Seifoddini, S. Hasani, Enhanced Mechanical and Magnetic Properties of $\left[\left(\mathrm{Fe}_{0.9} \mathrm{Ni}_{0.1}\right)_{77} \mathrm{Mo}_{5} \mathrm{P}_{9} \mathrm{C}_{7.5} \mathrm{~B}_{1.5}\right]_{99.9} \mathrm{Cu}_{0.1}$ Bulk Metallic Glass by Partial Annealing, Metallurgical and Materials Transactions A 50, 2019, pp. 2875-2885.

[9] M. Nabiałek, B. Jeż, K. Jeż, S. Walters, K. Błoch, The Total Core Losses in Bulk Amorphous Rods of $\mathrm{Fe}_{60} \mathrm{Co}_{10} \mathrm{Y}_{8-x} \mathrm{Ni}_{2+x} \mathrm{~B}_{20}$ Alloys (Where $x=0,1$ ), ACTA PHYSICA POLONICA A 137(3), 2020, pp. 350-354.

[10] B. Płoszaj, M. Nabiałek, K. Błoch, B. Koczurkiewicz, A.V. Sandu, M.M.A.B. Abdullah, A. Kalwik, B. Jeż, Total Core Losses and Dilatometric Properties of Bulk Amorphous FeBased Alloys, ACTA PHYSICA POLONICA A 138(2), 2020, pp. 221-223.

[11] W. Klement, R.H. Willens, P. Duwez, Non-crystalline Structure in Solidified Gold-Silicon Alloys, Nature 187 (4740), 1960, pp. 869-870.

[12] M. Nabiałek, The Influence of the Soaking Process on Magnetization Saturation and Coercivity Field of the Classic Amorphous Alloy $\mathrm{Fe}_{61} \mathrm{Co}_{10} \mathrm{Y}_{8} \mathrm{Nb}_{1} \mathrm{~B}_{20}$, Revista de Chimie 69(10), 2018, pp. 2819-2822. 
[13] Ansar Masood, H.A. Baghbaderani, K.L. Alvarez, J.M. Blanco, Z. Pavlovic, V. Ström, P. Stamenov, C.O. Mathuna, P. McCloskey, High-frequency power loss mechanisms in ultrathin amorphous ribbons, Journal of Magnetism and Magnetic Materials 519, 2021, 167469.

[14] A. Takeuchi, A. Inoue, Classification of Bulk Metallic Glasses by Atomic Size Difference, Heat of Mixing and Period of Constituent Elements and Its Application to Characterization of the Main Alloying Element, Material Transactions 46, 2005, pp. 2817-2829.

[15] T. Nagase, M. Suzuki, T. Tanaka, Formation of amorphous phase with crystalline globules in $\mathrm{Fe}-\mathrm{Cu}$-Si-B and $\mathrm{Fe}-\mathrm{Cu}-\mathrm{Zr}-\mathrm{B}$ immiscible alloys, Intermetallics 61, 2015, pp. 56-65.

[16] S. Flügge, Encyclopedia of physics. Volume XV, Low Temperature Physics II, SpringerVerlag, 1956, p.12.

[17] Z. Obuszko, Waga magnetyczna, Patent P 115655 (54077), 1967.

Received: January 28, 2021

Accepted: March 01, 2021 